\title{
P I 8-02. Peptide pulsed dendritic cells allows for induction of polyfunctional CD4+ $T$ cell responses and help CD8+ $T$ cell targeting subdominant CTL epitopes
}

\author{
A Fomsgaard*1, I Karlsson ${ }^{1}$, H Kløverpris ${ }^{1}$, J Bonde ${ }^{1}$, M Thorn ${ }^{1}$, \\ AE Pedersen ${ }^{2}$, L Vinner ${ }^{1}$, G Gram ${ }^{1}$, IM Svane ${ }^{3}$, J Gerstoft ${ }^{4}$ and G Kronborg${ }^{5}$
}

Address: ${ }^{1}$ Virology, Statens Serum Institut, Copenhagen, Denmark, ${ }^{2}$ University of Copenhagen, Copenhagen, Denmark, ${ }^{3}$ University Hospital Herlev, Copenhagen, Denmark, ${ }^{4}$ University Hospital Copenhagen, Copenhagen, Denmark and ${ }^{5}$ University Hospital Hvidovre, Copenhagen, Denmark

* Corresponding author

from AIDS Vaccine 2009

Paris, France. 19-22 October 2009

Published: 22 October 2009

Retrovirology 2009, 6(Suppl 3):P3 I I doi:I0.II86/I742-4690-6-S3-P3 I I

This abstract is available from: http://www.retrovirology.com/content/6/S3/P3I I

(C) 2009 Fomsgaard et al; licensee BioMed Central Ltd.

\section{Background}

To target HIV-1 specific CTL epitopes that are subdominant in the context of natural infection we designed a peptide based vaccine in order to induce a balanced CD4+ and CD8+ cellular immune response. We believe that inducing CD4+ T cell responses would provide help and allow for responses against sub-dominant epitopes to come forward.

\section{Methods}

In a phase I/II therapeutic HIV-1 vaccine trial 12 treatment naïve HIV-1 infected Danish individuals received $1 \times 10 \mathrm{e} 7$ autologous monocyte derived dendritic cells s.c. (week 0 , 2, 4 and 8) pulsed with 10 different peptides, 7 CTL epitopes from conserved regions of HIV-1 and two HIV-1 derived and one universal T helper epitope. Novel T cell responses were evaluated by intracellular cytokine staining for IFN- $\gamma$, TNF- $\alpha$ and IL-2.

\section{Results}

This mode of vaccination generated robust polyfunctional vaccine specific $\mathrm{CD} 4+\mathrm{T}$ cell responses sustained at the last evaluation, 6 months after the last immuniza-tion. Cytokine responses were dominated by TNF- $\alpha$ and IL-2 production, indicative of long-lived central memory cells. Moreover, in 12 out of 12 patient's vaccine specific CD8+ $\mathrm{T}$ cell responses were detected.

\section{Conclusion}

This suggests that this mode of vaccination, dendritic cells loaded with a combination of T helper and CTL epitope peptides, is a successful approach to target subdominant epitopes and the possibility to re-direct the immune response towards selected epitopes during chronic HIV-1 infection is an important proof of concept. 